\title{
Depth Profiles of Microplastics in Sediment Cores from Two Mangrove Forests in Northern Vietnam
}

\author{
Luu Viet Dung ${ }^{1,2, *}$, Truong Huu Duc ${ }^{1,2}$, Le Thi Khanh Linh ${ }^{1,2}$, Trinh Thi Dieu Ly ${ }^{2}$, Hoang Anh Duong ${ }^{2}$ \\ and Nguyen Thi My Hao ${ }^{2}$ \\ 1 Key Laboratory of Geoenvironment and Climate Change Response, VNU University of Science, Vietnam \\ National University, 334 Nguyen Trai, Thanh Xuan District, Hanoi 12000, Vietnam; \\ truonghuuduc_t61@hus.edu.vn (T.H.D.); lethikhanhlinh_t61@hus.edu.vn (L.T.K.L.) \\ 2 Faculty of Geology, VNU University of Science, Vietnam National University, 334 Nguyen Trai, Thanh Xuan \\ District, Hanoi 12000, Vietnam; trinhthidieuly_t62@hus.edu.vn (T.T.D.L.); \\ hoanganhduong_t63@hus.edu.vn (H.A.D.); nguyenthimyhao_t63@hus.edu.vn (N.T.M.H.) \\ * Correspondence: dungluuviet@gmail.com; Tel.: +84-904729009
}

Citation: Viet Dung, L.; Huu Duc, T.; Thi Khanh Linh, L.; Thi Dieu Ly, T.; Anh Duong, H.; Thi My Hao, N. Depth Profiles of Microplastics in Sediment Cores from Two Mangrove Forests in Northern Vietnam. J. Mar. Sci. Eng. 2021, 9, 1381. https:// doi.org/10.3390/jmse9121381

Academic Editors: Gert Everaert and Ana I. Catarino

Received: 9 November 2021

Accepted: 27 November 2021

Published: 4 December 2021

Publisher's Note: MDPI stays neutral with regard to jurisdictional claims in published maps and institutional affiliations.

Copyright: (c) 2021 by the authors. Licensee MDPI, Basel, Switzerland. This article is an open access article distributed under the terms and conditions of the Creative Commons Attribution (CC BY) license (https:/ / creativecommons.org/licenses/by/ $4.0 /)$.

\begin{abstract}
Plastics are essential materials that play critical roles in people's lives in the modern world. However, plastic pollution in the ocean has become a critical environmental problem due to the fact of its durability and long life span. In the present study, we analyze the contamination of microplastics in sediment cores from mangrove forests of the Red River Delta and Tien Yen Bay in Northern Vietnam. The results showed that the concentration of microplastics in sediment cores ranged from 0 to 4941 particles $/ \mathrm{kg}$, with four types of microplastics: microfiber, microfragment, microfoam, and microfilm. Microplastics were not observed in sediment samples lower than 65 and $70 \mathrm{~cm}$ core depth in sediment cores from the Tien Yen Bay and Red River Delta. The microplastic concentration in sediment cores from the Red River Delta was significantly higher than those of Tien Yen Bay, reflecting the influence of anthropogenic activities on microplastics pollution. The present results highlight that the accumulation of microplastics may have occurred a long time ago and tends to increase in the future. Further investigation on microplastic accumulation rates, sources of microplastics, and reducing plastic pollution is necessary to minimize the impacts of microplastic pollution on aquatic life and the environment.
\end{abstract}

Keywords: microplastics; mangrove sediment; Red River Delta; Tien Yen Bay

\section{Introduction}

Plastic products have been produced and widely used since the 1940s, playing important roles in many economic sectors and people's lives [1]. However, with the increasing demand for plastic products (estimated to be up to 12 billion tons by 2025 [2]), plastic wastes are increasingly affecting the environment, especially coastal ecosystems [2]. Every year, the ocean receives approximately 4.8-12.7 million tons of plastic waste from fishing activities, tourism, and especially the increasing amount of domestic and industrial wastes [3]. Most plastic components are difficult to biodegrade, and they are broken into smaller pieces by physical factors, such as UV rays and waves, and deposited in coral reefs and sediments. Pieces of plastic $<5 \mathrm{~mm}$ in size are called microplastics $[4,5]$. In recent years, large amounts of plastic waste discharged into the environment, causing environmental quality degradation and negatively affecting the coastal ecosystems [6]. Microplastics are classified into primary and secondary microplastics [7]. Primary microplastics are produced for the plastics industry with specific shapes and sizes and are usually spherical. Secondary microplastics are products of plastic waste during the decomposition process in the environment [7]. Microplastics are widespread in coastal and ocean environments, and they can float on the ocean's surface or settle in sediments throughout the world's oceans. Microplastics are widely distributed from coastal to offshore environments, even in 
Arctic Sea regions [8-10]. Studies on microplastics accumulation in sediments from coastal zones of China showed that large estuaries in this country are higly contaminated by microplastic wastes [11-15]. Recent studies have recorded the appearance of microplastics in the bodies of many fish, turtles, seabirds [16], plankton [17], and the digestive system of bivalves [18]. Microplastics accumulated in the organism can be enriched in the food chain, affecting many other species including humans. Moreover, microplastics can adsorb organic pollutants, heavy metals, and PCBs, causing harmful effects on various animals and ecosystems [19-21].

Research on microplastics pollution has expanded worldwide, focusing on the distribution and characteristics of microplastics in coastal marine environments. Unfortunately, there are few studies on microplastics pollution in developing countries, the largest source of untreated plastic waste discharges into the ocean. Vietnam is considered a significant source of marine plastic wastes (0.28-0.73 MMT/year) dumped into the ocean [3]. However, microplastics accumulation in sediment cores is rarely observed, particularly in Vietnam and Southeast Asia. A lack of information on plastic pollution makes government efforts to reduce plastic waste hard to implement in the future. In the present study, we analyzed microplastics in five mangrove sediment cores to understand the current status and temporal variations of microplastics pollution in Northern Vietnam. The research results will play essential roles in reducing microplastics pollution in coastal areas, particularly in Vietnam and Asia-Pacific regions.

\section{Materials and Methods}

\subsection{Study Area}

The present study was conducted in two mangrove forests of Northern Vietnam including the Red River Delta and Tien Yen Bay (Figure 1). The first sampling location in the Red River Delta belongs in the Tien Hai District, Thai Binh Province, Vietnam, with the dominant plantation mangrove species being Kandelia obovata and Sonneratia caseolaris. In Tien Yen Bay, the dominated mangrove species are Bruguiera gymnorrhiza, Avicenia marina, Kandelia obovata, and Rhizophora stylosa (Table 1). The true mangrove species, Aegiceras corniculatum, is widely distributed in both Tien Yen Bay and the Red River Delta and grows near tidal creeks and estuaries. The mangrove forests in the Red River Delta have been replanted since the 1990s with the dominant planted species being K. obovata and S. caseolaris, which play essential roles in coastal protection, pollutant filtration, and providing habitats for aquatic organisms. Mangrove forests and surrounding areas in the Red River Delta are vital stopovers and breeding sites for migratory birds and waterfowls. Mangrove forests in Tien Yen Bay are natural forests in northeastern Vietnam that play essential roles in biodiversity conservation and provide habitats for animals. All sampling sites are located in the monsoon climate zone, with the dry season from November to April and the rainy season from May to October. The Red River Estuary receives large amounts of pollutants from large cities and industrial areas in Northern Vietnam [22]. Mangroves in this area play an important role as a "natural filter" for pollutants, creating favorable conditions for microplastics accumulation. Tien Yen Bay is a semi-closed Bay with weak urbanization and industrial activities [23]. However, the fishing activities in Tien Yen Bay are highly concentrated in this area, with the main seafood products being peanut worms, clam, shrimps, and sea groupers.

\subsection{Field Sampling}

The sediment cores were collected by a peat sampler (Eijkelkamp Soil \& Water, The Netherlands) up to $1 \mathrm{~m}$ in depth at five sampling sites from the Red River Delta and Tien Yen Bay, Vietnam (Figure 1). The samples were immediately transferred in a cleaned PVC tube, wrapped with aluminum foils, and stored in a cool box until further analysis. The sediment samples were processed within $24 \mathrm{~h}$ of collection in a field laboratory near sampling sites. In the field laboratory, the outer layers of sediment cores $(\sim 0.5 \mathrm{~cm}$ in thickness) were removed and then sliced with a stainless-steel knife for reducing any 
contamination of plastic particles. The slicing intervals were 5 and $10 \mathrm{~cm}$ for the depths of $0-50 \mathrm{~cm}$ and 50-100 cm in sediment cores from the Red River Delta, respectively. In Tien Yen Bay, due to the high density of mangrove roots, the slicing intervals were modified to 10 and $15 \mathrm{~cm}$ for the depths of $0-50 \mathrm{~cm}$ and $50-100 \mathrm{~cm}$, respectively. All sliced samples were stored in washed polyethylene bags (three times washed with distilled water) on a cool box and then transported to the laboratory for further processing. The subsamples of mangrove sediment (approximately $5 \mathrm{~g}$ in weight) were also collected to analyze sediment grain size.

Table 1. The sampling sites' description in two mangrove forests in Northern Vietnam.

\begin{tabular}{|c|c|c|c|c|}
\hline Sample Site & Location & Type of Mangrove Forest & Dominant Mangrove Species & $\begin{array}{l}\text { Sedimentation } \\
\text { Rate }(\mathrm{cm} / \text { Year })\end{array}$ \\
\hline TH-01 & $\begin{array}{l}\text { Red River } \\
\text { Delta }\end{array}$ & $\begin{array}{l}\text { Re-plantation mangrove } \\
\text { forest }\end{array}$ & $\begin{array}{c}\text { Aegiceras cornicudatum, } \\
\text { Kandeliaobovata, and Sonneratia caseolaris }\end{array}$ & $1.2 \mathrm{~cm}[22]$ \\
\hline TH-02 & $\begin{array}{l}\text { Red River } \\
\text { Delta }\end{array}$ & $\begin{array}{l}\text { Re-plantation mangrove } \\
\text { forest }\end{array}$ & $\begin{array}{c}\text { Aegiceras cornicudatum and } \\
\text { Kandeliaobovata }\end{array}$ & $1.2 \mathrm{~cm}[22]$ \\
\hline TH-03 & $\begin{array}{l}\text { Red River } \\
\text { Delta }\end{array}$ & $\begin{array}{l}\text { Re-plantation mangrove } \\
\text { forest }\end{array}$ & $\begin{array}{l}\text { Aegiceras cornicudatum, } \\
\text { Kandeliaobovata, and Sonneratia caseolaris }\end{array}$ & $1.2 \mathrm{~cm}[22]$ \\
\hline TY-01 & Tien Yen Bay & Natural mangrove forest & $\begin{array}{c}\text { Avicenia marina, and Rhizophora } \\
\text { stylosa }\end{array}$ & $0.82 \mathrm{~cm}[24]$ \\
\hline TY-02 & Tien Yen Bay & Natural mangrove forest & $\begin{array}{l}\text { Avicenia marina, Kandelia obovata, and } \\
\text { Rhizophora stylosa }\end{array}$ & $0.82 \mathrm{~cm}[24]$ \\
\hline
\end{tabular}

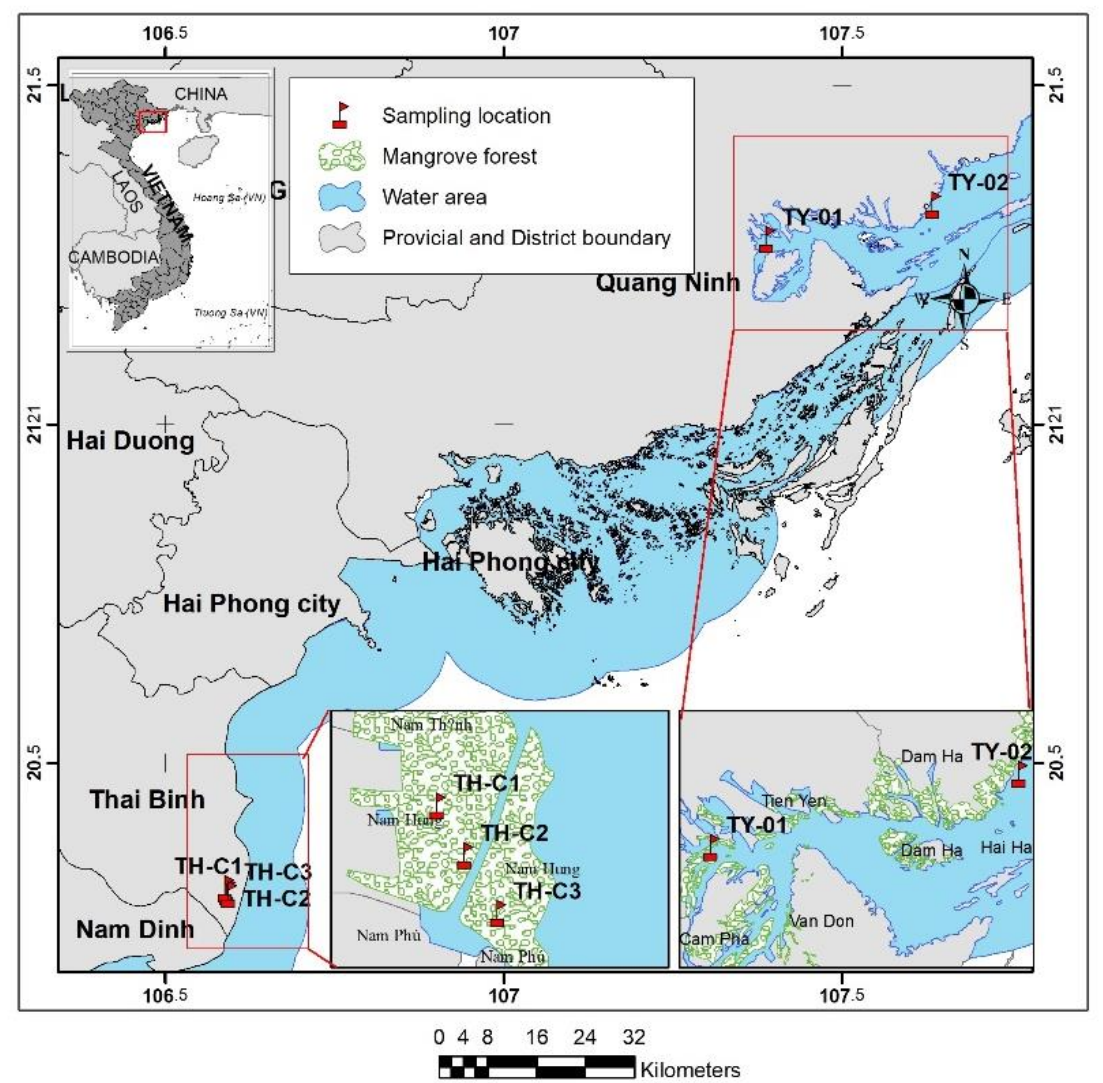

Figure 1. Map of the sampling locations in Northern Vietnam. 


\subsection{Sample Analysis}

\subsubsection{Sediment Grain Size Analysis}

The sediment grain size was analyzed by laser diffraction methods using the Horiba Partica LA-950 system. Before the analysis, all visible organic fragments in the samples were removed by hand using stainless-steel tweezers. Approximately $2 \mathrm{~g}$ of fresh sediment sample was placed in a ceramic cup, and then we added $10 \mathrm{~mL}$ of hydroperoxide $10 \%$ solution for organic matter oxidation in $24 \mathrm{~h}$. The organic matter removal process was repeated two or three times until all organic materials were decomposed. Due to the high clay and silt particle concentration in mangrove sediment samples, we added $2 \mathrm{~mL}$ of sodium hexametaphosphate $5 \%$ solution to each ceramic cup to reduce sediment flocculation $[25,26]$. All sediment samples in the ceramic cup were transferred in an ultrasonic bath for sonication $10 \mathrm{~min}$ before analysis. The sediment grain size was reported as the median size and grain size fractions (i.e., sand, silt, and clay contents). The number of samples was 45 and 18 for the Red River Delta and Tien Yen Bay, respectively.

\subsubsection{Microplastics Analysis}

The microplastics analysis method in the sediment cores followed US National Oceanic and Atmospheric Administration (NOAA)'s practices with a slightly modified procedure [21]. Briefly, approximately $50 \mathrm{~g}$ of fresh sediment samples were dried at $40{ }^{\circ} \mathrm{C}$ for $48 \mathrm{~h}$ or until constant weight. The dried sample was placed in a beaker, and we slowly added $20-50 \mathrm{~mL}$ of a $30 \%$ perodioxide solution. Then, approximately $10 \mathrm{~mL}$ of catalyst solution $\left(0.05 \mathrm{M} \mathrm{FeSO}_{4}\right.$ solution) was added to each beaker to enhance the oxidation rates of organic matter. The nearshore environment is the habitat of many benthic species with a high density of shell debris in the sediment. For samples with a lot of shell debris, approximately $10-20 \mathrm{~mL}$ of $1 \mathrm{M} \mathrm{HCl}$ solution was added to remove the carbonate component within $12 \mathrm{~h}$ (or until bubbles stopped appearing). The sample was sieved using a $0.3 \mathrm{~mm}$ test sieve (20 cm in diameter) to remove small sediment particles, and the residue on the sieve was washed into a beaker before being transferred to an electric oven to remove water at $40^{\circ} \mathrm{C}$ in $48 \mathrm{~h}$.

After removing organic matter, carbonate, and water, the samples were placed in $50 \mathrm{~mL}$ centrifuge tubes and filled with $1.6 \mathrm{~g} / \mathrm{L} \mathrm{ZnCl}_{2}$ solutions. The mixture was centrifuged at high speed (3000 RCF for $5 \mathrm{~min}$ ) 3 times to separate the microplastics (having lowdensity and floating on top of each tube). The microplastic particles floating on top were filtered through a filter membrane ( $47 \mathrm{~mm}$ diameter grid filter, pore size of $0.7 \mu \mathrm{m})$ using a Nagalene vacuum filter holder. During filtration, Milli-Q water was added to ensure no residual $\mathrm{ZnCl}_{2}$ on the filter membrane. After filtration, all filter membranes were stored in aluminum foil bags, then dried at $45^{\circ} \mathrm{C}$ to a constant weight. A stereomicroscope coupled with a digital camera (Euromex DC.5000) was used to determine microplastic particles in the sediments. The types of microplastics were identified according to the guidelines of the NOAA $[4,19]$.

All reagents and solutions were firstly filtered through $47 \mathrm{~mm}$ Whatman GF/F filters and then stored in a glass beaker before analysis to reduce the contaminants in the experiment. Aluminum foils covered all beakers for microplastics analysis during the experimental processes. For each sediment core, blank samples were performed during analysis to measure background contamination. If the contaminants were detected in a blank sample, the total microplastic in a batch of samples was substrated by the number of contaminated plastic particles. We found that two blank procedural samples were contaminated with 2 particles of microfibers during the experiment processes.

\subsubsection{Chemical Characteristics of Microplastic by FTIR Analysis}

Due to the small size and super lightweight of microplastics in sediment samples, the selected particles of microplastics were collected from filter paper to determine the chemical composition. We merged selected plastic particles in each sediment core before microplastics chemical identification by the FTIR method. Microplastic particles were finely 
ground with the $\mathrm{KBr}$ substrate using an agate mortar and pestle, then compressed by a compressor before being analyzed by the Jasco FTIR 4600 system at the University of Science, Vietnam National University, Hanoi. The FTIR analysis spectrum of the microplastics sample was compared and classified according to the chemical composition published by Gerrit Renner [27].

\subsubsection{Statistical Analysis}

Principal component analysis (PCA) was used to explain the relationship between the concentration of microplastics and sediment characteristics (Md, sand, silt, and clay contents). Pearson correlation was also applied to interpret the connection among the number of microplastics and sediment characteristics. The statistical difference of microplastics distribution in depth and the location was identified by non-parametric Kruskal-Wallis test. Statistical difference between groups was recorded when $p<0.05$. All statistical tests were performed by IBM SPSS v20.0.

\section{Results}

\subsection{Sediment Grain Size Distribution in Mangrove Forests}

The sediment samples from Tien yen Bay and the Red River Delta had high concentrations of silt and clay and varied along with the depth of the sediment cores. The Md of the sediment particles ranged from 11.55 to $45.66 \mu \mathrm{m}$ and 7.06 to $13.1 \mu \mathrm{m}$ in Tien Yen Bay and the Red River Delta, respectively. The Md of mangrove sediment in Tien yen Bay was significantly higher than those of the Red River Delta, and a similar trend was observed for sand content. However, there was no statistical difference between silt concentrations in sediment among sampling locations. Md value tends to be stable along with sediment depth, except core TY-01 showed an increasing trend from top to bottom of the core. The sediment grain size distribution indicated that the main sediment types in sampling locations were silty and sandy silt sediment for Tien Yen Bay and the Red River Delta, respectively.

\subsection{Microplastic Abundance in Sediment Core \\ 3.2.1. Microplastic Types in Mangrove Sediment Cores}

In the present study, we observed four types of microplastic in mangrove sediments including microfiber, microfoam, microfragment, and microfilm. All types of microplastics in two sampling locations are secondary plastics directly related to plastic wastes from inland and coastal areas. We did not focus on determining the color and size of each microplastic particle in the samples. However, the main colors of microplastics were mainly transparent, white, clear, blue, and green. We also recorded that most microplastic particles were smaller than $1 \mathrm{~mm}$ in all sediment cores. Microfiber was the most popular microplastic type in all sediment cores, ranging from 0 to 4253 particles $/ \mathrm{kg}$ in two sampling locations. The microfiber concentration from 0 to $50 \mathrm{~cm}$ in depth in sediment cores from Tien Yen Bay was statistically lower than those of the Red River Delta (Kruskal-Wallis, $p<0.05)$. A similar trend was detected in microfragment concentration, with the variation in microfragment ranging from 0 to 79 and 0 to 439 particles $/ \mathrm{kg}$ for Tien Yen Bay and the Red River Delta, respectively. However, a location difference for microplastic types was not observed in sediment cores from 50 to $10 \mathrm{~cm}$ in depth (Kruskal-Wallis, $p>0.05$, Table 2). The correlation between microplastic types and sediment characteristics was also not observed in the present study. Based on previous studies on sedimentation rates, we estimated that the microplastics existed in the sediment stratum from 1935 to 1959 and from 1953 to 1962 for Tien Yen Bay and the Red River Delta, respectively (Table 1, Figures 2 and 3). 

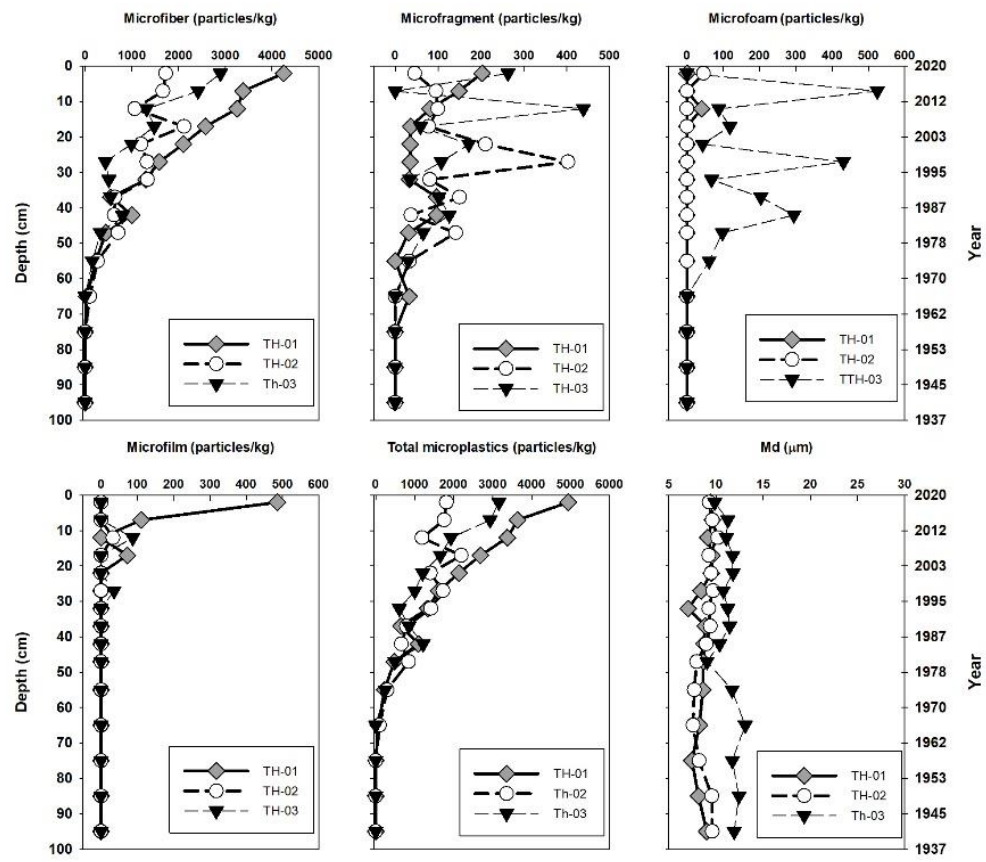

Figure 2. The characteristics of microplastics and sediment grain size in the Red River Delta. Data for the year axis were calculated from [22].
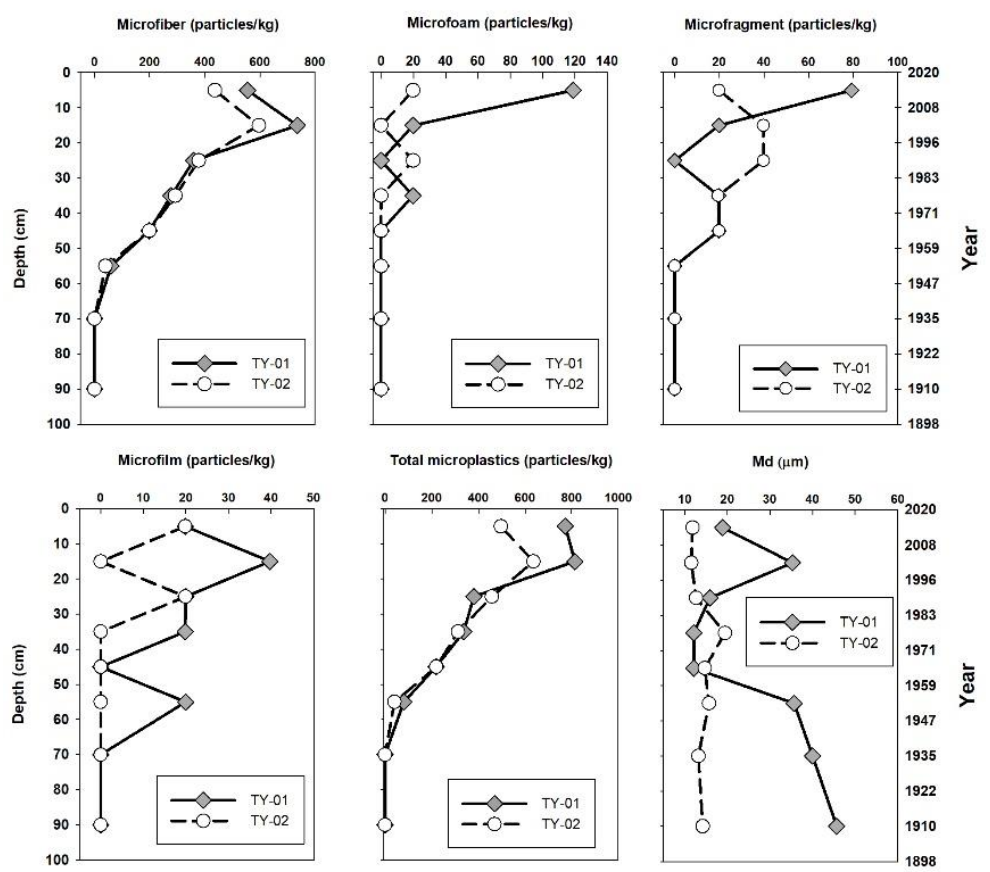

Figure 3. The characteristics of microplastics and sediment grain size in Tien Yen Bay. Data for the year axis were calculated from [24].

\subsubsection{Total Microplastics in Mangrove Sediment Cores}

The total microplastics in sediment cores ranged from 0 to 4941 and from 0 to 815 particles/kg for the Red River Delta and Tien Yen Bay, respectively. In all sampling locations, the total microplastics decreased from the top to the bottom of each core (Figures 2 and 3). The total microplastics in 0-50 cm deep sediment cores from Tien Yen Bay was significantly lower than those of the Red River Delta (Kruskal-Wallis, $p<0.05$ ). However, a similar trend was not observed for sediment samples from 50 to $100 \mathrm{~cm}$ in depth (Table 2). The microplastics in sediment samples from Tien Yen Bay were detected in the sediment layer from 50 
to $65 \mathrm{~cm}$, corresponding to the 1930-1950s [24]. In the Red River Delta, the microplastics were not detected in the sediment layer from 70 to $80 \mathrm{~cm}$ in depth, corresponding to the 1940-1960s [22]. These results suggested that microplastics have been present in mangrove sediments from Northern Vietnam since the 1950s.

Table 2. The Kruskal-Wallis test results between two sampling locations in Northern Vietnam.

\begin{tabular}{ccccccccccc}
\hline Depth Zone & & Md & Sand & Silt & Clay & MFB & MFA & MFO & MFI & MPs \\
\hline \multirow{2}{*}{$0-50 \mathrm{~cm}$} & Chi-Square & 21.370 & 19.142 & 3.750 & 21.370 & 15.244 & 13.016 & 0.000 & 2.874 & 17.518 \\
& $p$ & $<0.001$ & $<0.001$ & 0.053 & $<0.001$ & $<0.001$ & $<0.001$ & 0.986 & 0.090 & $<0.001$ \\
\multirow{2}{*}{$50-100 \mathrm{~cm}$} & Chi-Square & 12.273 & 12.353 & 12.273 & 12.273 & 0.077 & 1.324 & 0.400 & 2.500 & 0.138 \\
& $p$ & $<0.001$ & $<0.001$ & $<0.001$ & 0.000 & 0.781 & 0.250 & 0.527 & 0.114 & 0.711 \\
\hline
\end{tabular}

MFB, MFA, MFO, MFI, and MPs denote microfiber, microfragment, microfoam, microfilm, and total microplastics, respectively.

The PCA analysis was applied to determine the relationship between microplastics concentration and sediment characteristics (Md, sand, silt, and clay contents). The first factor accounted for $72.94 \%$ and $61.64 \%$ of the variance in Tien Yen Bay and the Red River Delta, respectively. The high loading of the first factors was observed in MFB, MFA, MFO, MFI, and MPs from both Tien Yen Bay and the Red River Delta, which indicated that all microplastic types might originate from the same sources (Figure 4). The second factor accounted for $32.15 \%$ and $26.26 \%$ of the variance in Tien Yen Bay and the Red River Delta, respectively. High loading factors of $\mathrm{Md}$ and sand content may relate to the grain size distribution of each sediment sample. Overall, the relationship between sediment characteristics and microplastics was not clearly observed in the present study.

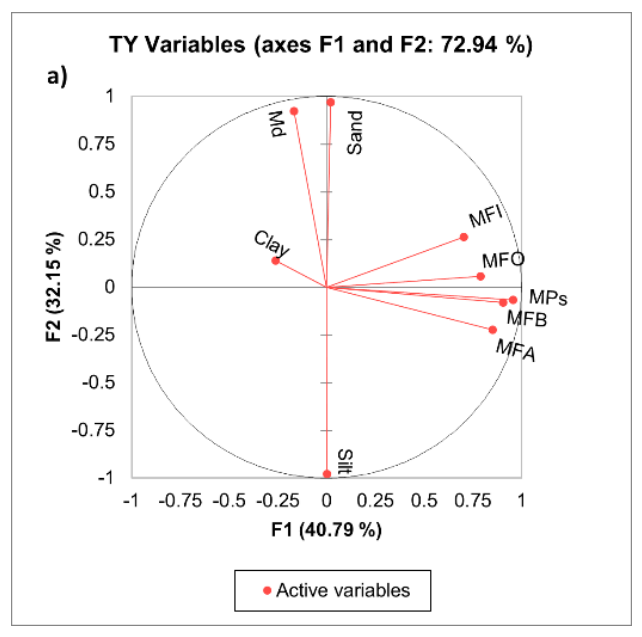

(a)

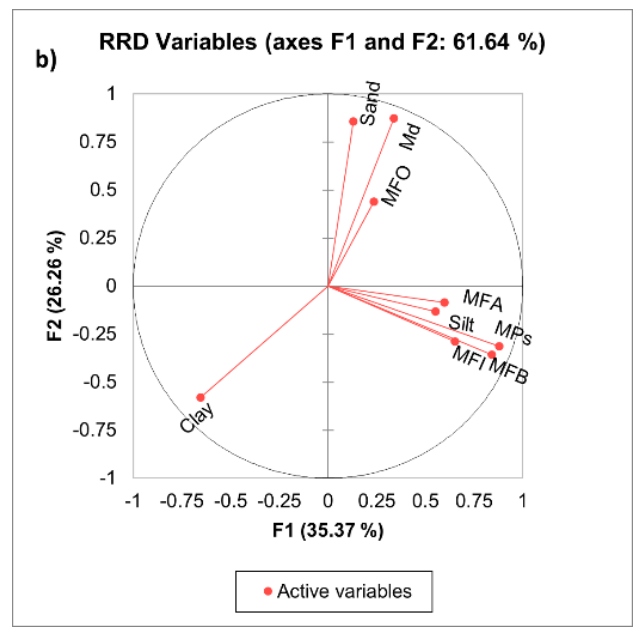

(b)

Figure 4. The PCA analysis among microplastics composition and sediment grain size: (a) all samples in Tien Yen Bay ( $n=18)$; (b) all samples in the Red River Delta $(n=45)$. MFB, MFA, MFO, MFI, and MPs denote microfiber, microfragment, microfoam, microfilm, and total microplastics.

\subsection{Microplastic Polymer Type in Sediment Core}

The results from the FTIR analysis of polymer type in microplastics samples in the Red River Delta and Tien Yen Bay were polyethylene (PE), polypropylene (PP), polystyrene (PS), polyethylene terephthalates (PET), polyamide (PA), and polyester (PLE). Popular plastics, such as polyvinyl chloride (PVC), acrylic, and polyurethane (PU), were not observed in all sediment cores from this area. However, the small microfibers or weathered particles in the samples may not be identifiable using the FTIR method. Microplastics' chemical characteristics indicated that the most popular plastics were found in sediment cores from mangrove forests in Northern Vietnam. 


\section{Discussion}

The present study showed that the concentration of microplastics in sediment from Northern Vietnam was significantly higher than those of other wetland types in Southeast Asia and China [28-30] and equivalent to the concentration of microplastics in estuaries in China $[11,31]$ (Table 3). The decreasing trend in microplastics abundance in sediment cores was similar to previous studies in Asia and Africa [12,29]. The vertical distribution of microplastics may relate to the accumulation of plastic wastes in Northern Vietnam since the 1950s. Most microplastics were observed from a 0 to $30 \mathrm{~cm}$ depth, and microfiber was the dominant plastic type in all sampling areas. Microplastic size in the study areas was mainly smaller than $1 \mathrm{~mm}$, similar to previous reports in the Australian estuary and Asia-Africa regions [29,32]. The small-sized microplastics in the study areas resulted from the breakdown of plastics in the sea environment [15] and the low dynamic environment in mangrove forests. A study in mangrove forests of Singapore reported that finer sediments have a high concentration of microplastics due to the microplastics retention in flocculation processes [28]. Overall, a clear relationship between sediment grain size and microplastics abundance was not observed in mangrove forests in Northern Vietnam.

The lower concentration of microplastics in sediment from Tien Yen Bay compared to the Red River Delta may be related to anthropogenic activities in Nothern Vietnam. The sampling site in the Red River Delta was located in the largest estuary in Northern Vietnam, which receives a large amount of untreated plastic wastes from the mainland. The increasing trend of microplastics in sediment cores from the Red River Delta from the 1990s to the present may relate to the economic development and growth of plastics consumption in Vietnam. A similar trend was also observed in Tien Yen Bay, with the concentration of microplastics increasing from the 1980s to the present (Figure 3). Recent research in the East China Sea indicated that microplastics concentration in sediment cores was directly related to plastic consumption and production [12], and a similar trend was observed in Northern Vietnam. The other microplastic sources may relate to crossborder transportation of plastic wastes in the ocean environment, which brings floating plastic wastes from developed countries in the Asia-Pacific region to the study areas [33]. Therefore, an international framework in the Asia-Pacific region for reducing marine debris and microplastics pollution is necessary to be implemented for enhancing environmental protection and conservation [34].

Table 3. The microplastics distribution in mangrove and wetland sediments from this study and selected regions.

\begin{tabular}{|c|c|c|c|c|}
\hline Location & Type of Wetlands & Plastic Particle Size (mm) & $\begin{array}{l}\text { Total Microplastics } \\
\text { (Particles/kg) }\end{array}$ & Data Sources \\
\hline Tien Yen Bay, Vietnam & Mangrove forest & $0.3-5$ & $0-815$ & This study \\
\hline Red River Delta, Vietnam & Mangrove forest & $0.3-5$ & $0-4941$ & This study \\
\hline Thanh Hoa, Vietnam & Tidal flats & $0.25-5$ & $2921-5365$ & [35] \\
\hline Singapore & Mangrove forest & $0.02-5$ & $12-62.8$ & [28] \\
\hline Gulf of Thailand & Bay & $0.3-5$ & $83-165$ & [29] \\
\hline $\begin{array}{l}\text { Andong salt marsh, } \\
\text { Hangzhou Bay, China }\end{array}$ & Saltmarsh & $0.1-5$ & $40-480$ & [12] \\
\hline Hong Kong & Bay & $0.1-5$ & $44-458$ & [36] \\
\hline Changjiang Estuary, China & Estuary and tidal flats & $<5$ & $20-340$ & [37] \\
\hline $\begin{array}{l}\text { Sishili Bay, } \\
\text { North Yellow Sea, China }\end{array}$ & Estuary and bay & $<5$ & $140-1873$ & [30] \\
\hline Sanggou Bay, China & Bay and estuary & $<5$ & 699-2824 & [14] \\
\hline $\begin{array}{c}\text { Pearl River Estuary, South } \\
\text { China }\end{array}$ & Mangrove forest & $<5$ & $100-7900$ & {$[31]$} \\
\hline Brisbane River, Australia & River & $<5$ & $10-520$ & [38] \\
\hline Southeast of China & Mangrove forest & $0.05-5$ & $8.3-5738.3$ & [13] \\
\hline Tampay Bay, Florida & Bay & $<5$ & $30-790$ & [39] \\
\hline
\end{tabular}


Table 3. Cont.

\begin{tabular}{ccccc}
\hline Location & Type of Wetlands & Plastic Particle Size (mm) & $\begin{array}{c}\text { Total Microplastics } \\
\text { (Particles/kg) }\end{array}$ & Data Sources \\
\hline Guanabara Bay, Brazilian & Bay & $0.1-5$ & $160-1000$ & {$[40]$} \\
Jinjang Enstuary, China & Estuary & $<5$ & $980-2340$ & {$[11]$} \\
Jagir Estuary, Indonesida & Estuary & $0.3-5$ & $<5-590$ & {$[41]$} \\
Liaohe Estuary, china & Estuary & $<5-220$ & {$[1739-2153$} & {$[42]$} \\
Xiangshan Bay, China & Bay & $<5$ & $560-4205$ & {$[15]$} \\
South Yellow Sea, China & Sea & $1-5$ & 258 & {$[44]$} \\
Pearl River, China & Estuary & $<5$ & \\
\hline
\end{tabular}

Both natural conditions and anthropogenic activities have also influenced the spatial distribution of microplastics sediment cores. Tien Yen Bay is a closed bay with a water current from the North and exchanging water with the Gulf of Tonkin through two small channels [45], indicating that sources of microplastics may relate to local anthropogenic activities. Additionally, microplastic types in sediment cores are secondary plastics, mainly originating from untreated plastics wastes discharged to the coastal marine environment. The chemical composition of microplastics in sediment (i.e., PE, PP, PS, PET, $\mathrm{PA}$, and polyester) suggested that the sources of microplastics come from households and aquaculture products such as fishnet, clothes, styrofoam, bottles, and others. The spatial variation of microplastics in the Red River Delta also supported this assumption, with a high concentration of microplastics observed in sediment cores near dikes and aquaculture zones. Therefore, the concentration of microplastics has a positive relationship with anthropogenic activities.

The vertical abundance of microplastics in sediment core is influenced by sedimentation rates, anthropogenic activities, and other natural processes. The sedimentation rates are influenced by mangrove standings and the tidal dynamic in mangrove forests [22,46,47]. These processes may be affecting the accumulation of microplastics in sediment cores. In mangrove forests, the bioturbation of mangrove crabs has changed sediment properties [48], and microplastics in surface sediment can be transferred into deeper layers through crab burrows on the forest floor. Furthermore, the anthropogenic activities of local people, such as aquatic organism harvesting in mangrove forests and fishing, may disturb the sediment stratum, leading to microplastic contamination in deeper sediment layers. Based on previous sediment dating data, the microplastics contamination in sediment cores from Northern Vietnam may have occurred from the 1950s to the 1970s. Further analysis, such as fine scales and associated radionuclides methods, such as Pb-210 and Cs-137, is necessary to clarify this process.

\section{Conclusions}

The present study showed that the mangrove sediments in Northern Vietnam had a high concentration of microplastics, mainly originating from anthropogenic wastes. Microplastics contamination in sediments from Northern Vietnam was similar to microplastics pollution reports in developing countries in the Asia-Pacific region. The depth variation of microplastics indicated that the microplastics might exist in sediment from 40 to 50 years ago. Sedimentation rate analysis using radionuclides methods, such as Pb-210 and Cs-137, is necessary to confirm the temporal changes in microplastics in the environment. The present study is the first observation of microplastics contamination in sediment cores from Vietnam's mangrove forests and coastal areas. Further investigation toward the identification of the sources of microplastics is necessary to reduce microplastics pollution in Vietnam and Asia-Pacific regions. 
Author Contributions: Conceptualization, L.V.D. and T.H.D.; methodology, L.V.D. and T.H.D.; analysis, T.H.D., T.T.D.L., N.T.M.H. and H.A.D.; writing—original draft preparation, L.V.D., T.H.D. and L.T.K.L.; writing-review and editing: L.V.D., L.T.K.L. and T.H.D. All authors have read and agreed to the published version of the manuscript.

Funding: This research was funded by the Vietnam National University, Hanoi (VNU), under project number: QG.19.01.

Institutional Review Board Statement: Not applicable.

Informed Consent Statement: Not applicable.

Data Availability Statement: The data in this study are available from the corresponding author.

Acknowledgments: The authors are grateful to the staff at the Tien Hai Nature Reserve, Vietnam, for their support during field sampling. We express our sincere thanks to the anonymous reviewers for their critical reviews and comments which significantly improved the manuscript

Conflicts of Interest: The authors declare no conflict of interest. The funders had no role in the design of the study; in the collection, analyses, or interpretation of data; in the writing of the manuscript or in the decision to publish the results.

\section{References}

1. Thompson, R.C.; Swan, S.H.; Moore, C.J.; Vom Saal, F.S. Our plastics age. Philos. Trans. R. Soc. B 2009, 346, 1973-1976. [CrossRef]

2. Henry, B.; Laitala, K.; Klepp, I.G. Microfibres from apparel and home textiles: Prospects for including microplastics in environmental sustainability assessment. Sci Total Environ. 2019, 652, 483-494. [CrossRef]

3. Jambeck, J.R.; Geyer, R.; Wilcox, C.; Siegler, T.R.; Perryman, M.; Andrady, A.; Narayan, R.; Law, K.L. Plastic waste inputs from land into the ocean. Science 2015, 347, 768-771. [CrossRef]

4. Masura, J.; Baker, J.; Foster, G.; Arthur, C. Laboratory Methods for the Analysis of Microplastics in the Marine Environment: Recommendations for Quantifying Synthetic Particles in Waters and Sediments. 2015. Available online: https://repository. oceanbestpractices.org/handle/11329/1076 (accessed on 18 October 2021).

5. Thompson, R.C. Plastic debris in the marine environment: Consequences and solutions. Mar. Nat. Conserv. Eur. 2006, 193, 107-115.

6. Carbery, M.; O'Connor, W.; Palanisami, T. Trophic transfer of microplastics and mixed contaminants in the marine food web and implications for human health. Environ. Int. 2018, 115, 400-409. [CrossRef]

7. Duis, K.; Coors, A. Microplastics in the aquatic and terrestrial environment. Environ. Sci. Eur. 2016, 28, 2. [CrossRef]

8. Van Cauwenberghe, L.; Vanreusel, A.; Mees, J.; Janssen, C.R. Microplastic pollution in deep-sea sediments. Environ. Pollut. 2013, 182, 495-499. [CrossRef]

9. Uddin, S.; Fowler, S.W.; Uddin, M.F.; Behbehani, M.; Naji, A. A review of microplastic distribution in sediment profles. Mar. Pollut. Bull. 2021, 163. [CrossRef] [PubMed]

10. La Daana, K.K.; Johansson, C.; Frias, J.; Gardfeldt, K.; Thompson, R.C.; O'Connor, I. Deep sea sediments of the Arctic Central Basin: A potential sink for microplastics. Deep Sea Res. Part I: Oceanogr. Res. Pap. 2019, 145, 137-142.

11. Deng, J.; Guo, P.; Zhang, X.; Su, H.; Zhang, Y.; Wu, Y. Microplastics and accumulated heavy metals in restored mangrove wetland surface sediments at Jinjiang Estuary (Fujian, China). Mar. Pollut. Bull. 2020, 159, 111482. [CrossRef]

12. Li, J.; Huang, W.; Xu, Y.; Jin, A.; Zhang, D.; Zhang, C. Microplastics in sediment cores as indicators of temporal trends in microplastic pollution in Andong salt marsh, Hangzhou Bay, China. Reg. Stud. Mar. Sci. 2020, 35, 101149. [CrossRef]

13. Zhou, Q.; Tu, C.; Fu, C.; Li, Y.; Zhang, H.; Xiong, K.; Zhao, X.; Li, L.; Waniek, J.J.; Luo, Y. Characteristics and Distribution of Microplastics in the Coastal Mangrove Sediments of China. Sci. Total Environ. 2019, 703. [CrossRef]

14. Sui, Q.; Zhang, L.; Xia, B.; Chen, B.; Sun, X.; Zhu, L.; Wang, R.; Qu, K. Spatiotemporal distribution, source identification and inventory of microplastics in surface sediments from Sanggou Bay, China. Sci Total Env. 2020, 723, 138064. [CrossRef]

15. Wang, J.; Wang, M.; Ru, S.; Liu, X. High levels of microplastic pollution in the sediments and benthic organisms of the South Yellow Sea, China. Sci Total Env. 2019, 651, 1661-1669. [CrossRef]

16. Derraik, J.G. The pollution of the marine environment by plastic debris: A review. Mar.Pollut.Bull 2002, 44, 842-852. [CrossRef]

17. Cole, M.; Lindeque, P.; Fileman, E.; Halsband, C.; Goodhead, R.; Moger, J.; Galloway, T.S. Microplastic Ingestion by Zooplankton. Environ. Sci. Technol. 2013, 47. [CrossRef]

18. Bour, A.; Haarr, A.; Keiter, S.; Hylland, K. Environmentally relevant microplastic exposure affects sediment-dwelling bivalves. Env. Pollut 2018, 236, 652-660. [CrossRef]

19. Brennecke, D.; Duarte, B.; Paiva, F.; Caçador, I.; Canning-Clode, J. Microplastics as vector for heavy metal contamination from the marine environment. Estuar. Coast. Shelf Sci. 2016, 178, 189-195. [CrossRef]

20. Charles, J.M. Synthetic polymers in the marine environment: A rapidly increasing, long-term threat, Synthetic polymers in the marine environment: A rapidly increasing, long-term threat. Environ. Res. 2008, 108, 131-139. 
21. Gallo, F.; Fossi, C.; Weber, R.; Santillo, D.; Sousa, J.; Ingram, I. Marine litter plastics and microplastics and their toxic chemicals components: The need for urgent preventive measures. Environ. Sci. Eur. 2018, 30, 13. [CrossRef]

22. Tue, N.T.; Quy, T.D.; Amano, A.; Hamaoka, H.; Tanabe, S.; Nhuan, M.T.; Omori, K. Historical profiles of trace element concentrations in mangrove sediments from the Ba Lat Estuary, Red River, Vietnam. Waterairsoil Pollut. 2012, 223, 1315-1330. [CrossRef]

23. Quy, T.D.; Tue, N.T. Spatial distribution of total organic carbon (TOC), total nitrogen (TN), TOC/TN ratio, and stable carbon isotopes value $(\delta 13 C)$ in surface sediments of Tien Yen Bay, northeast Vietnam (In Vietnamese). Vietnam J. Earth Sci. 2011, 33, 616-624.

24. Hoai, N.D.; Duc, T.T.; Van, H.D.; Son, H.P.; Manh, H.N.; Dinh, L.T.; Xiaoyong, D.; Dac, V.N. Sedimentation rates and heavy metal concentrations in the tidal flats of North Vietnam. Pol. J. Environ. Stud. 2019, 28, 3721-3733. [CrossRef]

25. Ryżak, M.; Bieganowski, A. Methodological aspects of determining soil particle-size distribution using the laser diffraction method. J. Plant Nutr. Soil Sci. 2011, 174, 624-633. [CrossRef]

26. Fisher, P.; Aumann, C.; Chia, K.; O’Halloran, N.; Chandra, S. Adequacy of laser diffraction for soil particle size analysis. PLoS ONE 2017, 12, e0176510. [CrossRef]

27. Renner, G.; Schmidt, T.; Schram, J. Characterization and Quantification of Microplastics by Infrared Spectroscopy. In Characterization and Analysis of Microplastics; Kruze, Z., Ed.; Comprehensive Analytical Chemistry, 2017; Volume 75, pp. 67-118. Available online: https:/ / www.semanticscholar.org/paper/Chapter-4-Characterization-and-Quantification-of-by-Renner-Schmidt/a8 77410878a535cd57ae1d108484fa322f83b41c (accessed on 18 October 2021).

28. Nor, N.H.M.; Obbard, J.P. Microplastics in Singapore's coastal mangrove ecosystems. Mar. Pollut. Bull. 2014, 79, 278-283. [CrossRef]

29. Matsuguma, Y.; Takada, H.; Kumata, H.; Kanke, H.; Sakurai, S.; Suzuki, T.; Itoh, M.; Okazaki, Y.; Boonyatumanond, R.; Zakaria, M.P.; et al. Microplastics in Sediment Cores from Asia and Africa as Indicators of Temporal Trends in Plastic Pollution. Arch. Environ. Contam. Toxicol. 2017, 73, 230-239. [CrossRef]

30. Zhang, B.; Wu, D.; Yang, X.; Teng, J.; Liu, Y.; Zhang, C.; Zhao, J.; Yin, X.; You, L.; Liu, Y.; et al. Microplastic pollution in the surface sediments collected from Sishili Bay, North Yellow Sea, China. Mar Pollut Bull 2019, 141, 9-15. [CrossRef]

31. Zuo, L.; Sun, Y.; Li, H.; Hu, Y.; Lin, L.; Peng, J.; Xu, X. Microplastics in mangrove sediments of the Pearl River Estuary, South China: Correlation with halogenated flame retardants' levels. Sci. Total Environ. 2020, 725, 138344. [CrossRef]

32. Willis, K.A.; Eriksen, R.; Wilcox, C.; Hardesty, B.D. Microplastic distribution at different sediment depths in an urban estuary. Front. Mar. Sci. 2017, 4, 419. [CrossRef]

33. Sterl, M.F.; Delandmeter, P.; van Sebille, E. Influence of barotropic tidal currents on transport and accumulation of floating microplastics in the global open ocean. J. Geophys. Res. Ocean. 2020, 125, e2019JC015583. [CrossRef]

34. Sereda, A.V.; Mikhaylichenko, Y.G.; Baklanov, P.Y.; Kachur, A.N.; Lappo, A.D.; Danilova, L.V. Contribution of an Integrated Maritime Policy to the Dialogue of Civilisations: The Asia-Pacific Case. J. Mar. Sci. Eng. 2021, 9, 610. [CrossRef]

35. Dung, L.V.; Duc, T.H.; Ha, N.T.H.; Tung, N.D.; Tue, N.T.; Hieu, P.V.; Dinh, N.Q.; Nhuan, M.T. Method for the analysis of microplatics in the tidal flat sediments, case study of Da Loc Commune, Hau Loc District, Thanh Hoa Province (in Vietnamese). Vietnam J. Hydrometeorol. 2020, 715, 1-12. [CrossRef]

36. Tsang, Y.Y.; Mak, C.W.; Liebich, C.; Lam, S.W.; Sze, E.T.; Chan, K.M. Microplastic pollution in the marine waters and sediments of Hong Kong. Mar.Pollut.Bull 2017, 115, 20-28. [CrossRef]

37. Peng, G.; Zhu, B.; Yang, D.; Su, L.; Shi, H.; Li, D. Microplastics in sediments of the Changjiang Estuary, China. Environ. Pollut. 2017, 225, 283-290. [CrossRef]

38. He, B.; Goonetilleke, A.; Ayoko, G.A.; Rintoul, L. Abundance, distribution patterns, and identification of microplastics in Brisbane River sediments, Australia. Sci. Total Environ. 2020, 700, 134467. [CrossRef]

39. McEachern, K.; Alegria, H.; Kalagher, A.L.; Hansen, C.; Morrison, S.; Hastings, D. Microplastics in Tampa Bay, Florida: Abundance and variability in estuarine waters and sediments. Mar. Pollut. Bull. 2019, 148, 97-106. [CrossRef]

40. Alves, V.E.; Figueiredo, G.M. Microplastic in the sediments of a highly eutrophic tropical estuary. Mar. Pollut. Bull. 2019, 146, 326-335. [CrossRef] [PubMed]

41. Firdaus, M.; Trihadiningrum, Y.; Lestari, P. Microplastic pollution in the sediment of Jagir Estuary, Surabaya City, Indonesia. Mar. Pollut. Bull. 2020, 150, 110790. [CrossRef]

42. Xu, Q.; Xing, R.; Sun, M.; Gao, Y.; An, L. Microplastics in sediments from an interconnected river-estuary region. Sci. Total Environ. 2020, 729, 139025. [CrossRef]

43. Chen, M.; Jin, M.; Tao, P.; Wang, Z.; Xie, W.; Yu, X.; Wang, K. Assessment of microplastics derived from mariculture in Xiangshan Bay, China. Environ. Pollut. 2018, 242, 1146-1156. [CrossRef] [PubMed]

44. Fan, Y.; Zheng, K.; Zhu, Z.; Chen, G.; Peng, X. Distribution, sedimentary record, and persistence of microplastics in the Pearl River catchment, China. Environ. Pollut. 2019, 251, 862-870. [CrossRef] [PubMed]

45. Quy, T.D.; Tue, N.T.; Nhuan, M.T. Spatial distribution of trace elements in surface sediments of Tien Yen Bay, northeast Vietnam. Vietnam J. Earth Sci. 2012, 34, 10-17.

46. Adame, M.F.; Neil, D.; Wright, S.F.; Lovelock, C.E. Sedimentation within and among mangrove forests along a gradient of geomorphological settings. Estuar. Coast. Shelf Sci. 2010, 86, 21-30. [CrossRef] 
47. van den Bergh, G.D.; Boer, W.; Schaapveld, M.A.S.; Duc, D.M.; van Weering, T.C.E. Recent sedimentation and sediment accumulation rates of the Ba Lat prodelta (Red River, Vietnam). J. Asian Earth Sci. 2007, 29, 545-557. [CrossRef]

48. McCraith, B.J.; Gardner, L.R.; Wethey, D.S.; Moore, W.S. The effect of fiddler crab burrowing on sediment mixing and radionuclide profiles along a topographic gradient in a southeastern salt marsh. J. Mar. Res. 2003, 61, 359-390. [CrossRef] 